\title{
Integrated Motivation Model of Entrepreneurial Team
}

\author{
Jie Chen \\ International School, Jinan University \\ Guangzhou, China \\ tbrookchen@jnu.edu.cn \\ brookchen@126.com
}

Keywords: Integrated Motivation Model, Entrepreneurial Team, Team Evolution

\begin{abstract}
Members of the entrepreneurial team play a vital role in new venture's survival and further development. Because of the differences in the development and the initial endowment of human capital, the lack of the appropriate motivation among entrepreneurial team members will lead to the failure of these startups. An integrated motivation model is proposed according to the different stages which targets at entrepreneurial teams, from major relation governance supplemented by contract governance at team building stage, while from major relation governance supplemented by contract governance at developing and adjourning stage.
\end{abstract}

\section{Introduction}

Team has become the core of the new venture (Cooper\& Daily,1997). Most startups are founded by the entrepreneurial team. Research has shown that teams tend to start innovative ventures during the first few years of their existence. [1]Especially new growth-oriented enterprises, is usually founded by the entrepreneurial team consisting of two or more founders (Cooney,2005; Cooper et al. , 1997). Although the team has become more and more common, but in practice, team management was not an easy, which is full of differences and conflicts in team interaction.

- An integrated and dynamic motivation model will solve incentive problems among entrepreneurial team members and direct further research in this field.

\section{Entrepreneurial Teams}

With the complexity of technology, intensity of competition, founder of the enterprise is no longer personal, but often a team. Team cooperation receives more and more attention, but the critical consensus to academic definition of the entrepreneurial team has not been reached.

Compared to a solo entrepreneur, an entrepreneurial team appears to cope more successfully with uncertainties and volatilities in an innovative start-up, where flexibility and complexity of decision making is imperative (Vesper, 1990). Hence, an understanding of entrepreneurial teams is essential in order to comprehend the creation and performance of new ventures.

Additionally, a body of research had begun (Cooper and Bruno, 1977) which suggested that firms founded by entrepreneurial teams were more likely to achieve fast growth than firms founded by lone entrepreneurs. [2]

It is argued that, given the variety of entrepreneurial teams and their various associated challenges, "Any definition that goes beyond the number of members and their common but possibly unequal concern for a small set of super ordinate goals, which are themselves subject to negotiation, is really seeking to distinguish effective teams rather than teams" (Schjoedt et al., 2013, pp. 3-4). Thus, for the purposes of this study, an entrepreneurial team is described as consisting of two or more individuals who hold shares in the firm, work actively in the venture and exert influence upon the strategic decision making within the venture (Almer-Jarz et al., 2008), during the early phase (Schjoedt and Kraus, 2009) (up to eight years including pre start-up and founding) of the development of the venture. The term "development of venture" highlights the dynamic nature of the firms and 
acknowledges that team members can join (or leave) at any stage of the maturation of the firm (Cooney, 2005).Thus, the definition encompasses entrepreneurial teams at different phases of the life cycle and is not solely restricted to a pre start-up phase. [3]

\section{Integrated Motivation Model of Entrepreneurial Teams}

\section{Team Building Stage}

The experience of Human resources plays a vital role for the growth of startups. Studies have shown that human experience has a significant positive impact on business performance. Resource dependence theory assumes that all the enterprises in terms of resource acquisition is incapable of self-sufficient. For new ventures, which has a "new" and "minor" defects, has much less access to adequate resources. To survive or to succeed, startups must obtain resources from the environment. For newly created enterprises, human resources are particularly important.

Barney (1991) from a strategic resources view found among all resources, only human resources in various venture capital evaluation system are considered to be a very important factor in startups. If the new venture's goal is to achieve sustainable competitive advantage, the non human resources such as financial resources materials resources do not play a decisive role achieving the goal.

Staurt (1987) and Timmons (1992) noted that human capital is a key factor to business performance in high-tech startups. A venture's success often depends on whether there are suitable team members, rather than a product, market or capital.

At team building stage the capability and personal traits linked to entrepreneurial ship team have not been proven, the motivation rely more on relation governance such as mutual recognition and trust than contract governance.Figurel shows the motivation model at this stage shows relation incentives in the first place, contract governance in the second place.

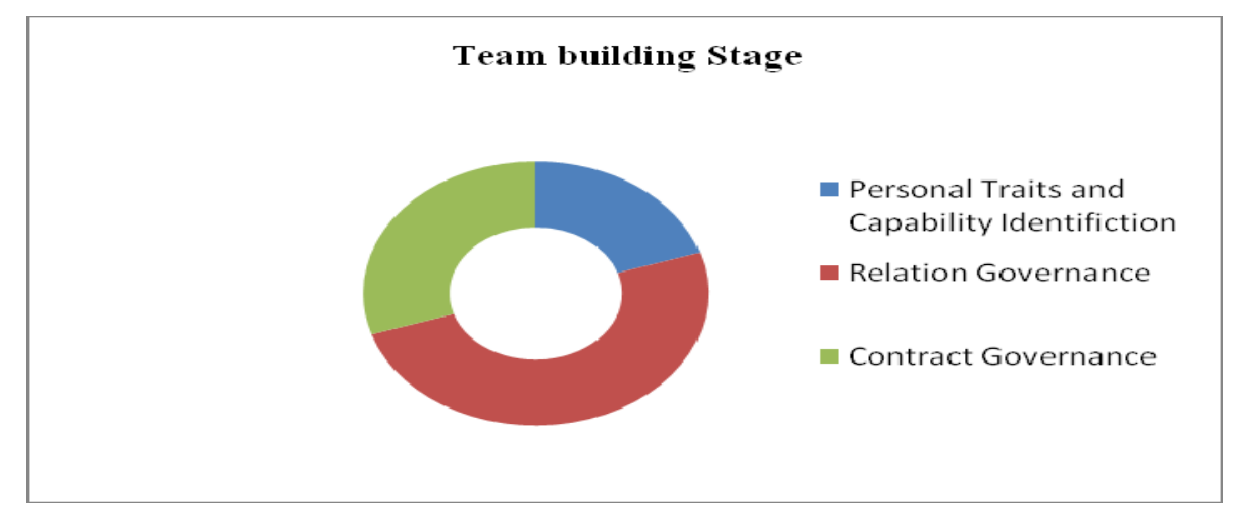

Figure 1.Motivation Model for Team Building Stage

\section{Performing and Adjourning Stage}

At developing stage, since team human capital has been gradually confirmed among entrepreneurial team members, motivation by relationships governance is weaken while contract governance becomes the dominant and effective motivation method.

In terms of clear accountabilities, responsibilities, rights and benefits of entrepreneurial team We adopt the theory of corporate governance and enterprise alliances governance (Poppo\&Zenger,2002;Za-heer and Venkatraman,1995), contract management becomes the formal form of team governance which form a formal rules to be followed in ownership allocation, compensation allocation and autonomy allocation by entrepreneurial team members.

\section{Ownership allocation}

Shareholders equity mainly refers to rights in capital gains and participation in major decision making and selection of managers of the company. Start-ups are lack of resources, only with 
unverified human capital (Bhide,1999); in other words, verifiable and tangible resources are very limited, the only intangible human capital has not yet been tested by the market. The original equity allocation in this case must be based on mutual recognition and trust as a kind option of expediency, which should further adjusted with different phases. If equity is configured to reflect the growth of differences entrepreneur human capital, which leads to clear and transparent expectation, and to produce effective team performance, hence better avoid risks, maintain operational efficiency of enterprises and voluntarily correct actions needed all of this help to increase performance of Entrepreneurial team.

\section{Compensation allocation}

Corporation law revised in 2006 takes the practical needs of China into account, expand dividend distribution rights in shareholders ' agreement and the company articles of incorporation, shareholders get dividends in proportion to the amount or the share, except for shareholders own agreement which is not in accordance with the principle of distribution of dividends. This amendment fully affirmed the importance of human capital which indicates dividend distribution does not necessarily have to be based on the proportion of shares but can be used as an important basis for dividend distribution of human capital. For new ventures, the innovation of the system protects initial resource endowment-poor entrepreneurs, protecting their human capital property rights which can effectively mobilize the enthusiasm of entrepreneurs. As new ventures Executive benefits of entrepreneurial team which also include remuneration and other incentive compensation.

As business owner, proportion of dividend distribution is essential to keep the stability, while as a reward for executives they could be flexible to change. The former can solve problem of long-term incentive for entrepreneurial team, the later can solve the short-term problem. Research in corporate governance shows that incentive-compatible top management team compensation structures that help improve business performance (Carpenter and Sanders, 2002)., entrepreneurial team based on human capital incentive income distribution can help solve the problem of incentive compatibility,

\section{Managerial autonomy}

Entrepreneurial decision-making autonomy reflects at the company's strategic and managerial levels. Team members are not only involved in strategic decisions, but also according to their specific strength as the specialist in human resource are responsible for a particular function. [4]On the functions of management, members can enjoy full management autonomy (managerial autonomy, Dill, 1958) this will effectively exert the strength both as an individual and team member and avoid operating risks, maintain operational efficiency to improve startup performance.

Figures 2 indicates that at performing and adjourning stage, since team human capital has been gradually confirmed among entrepreneurial team members, motivation by relationships governance is weaken while contract governance becomes the dominant and effective motivation method.

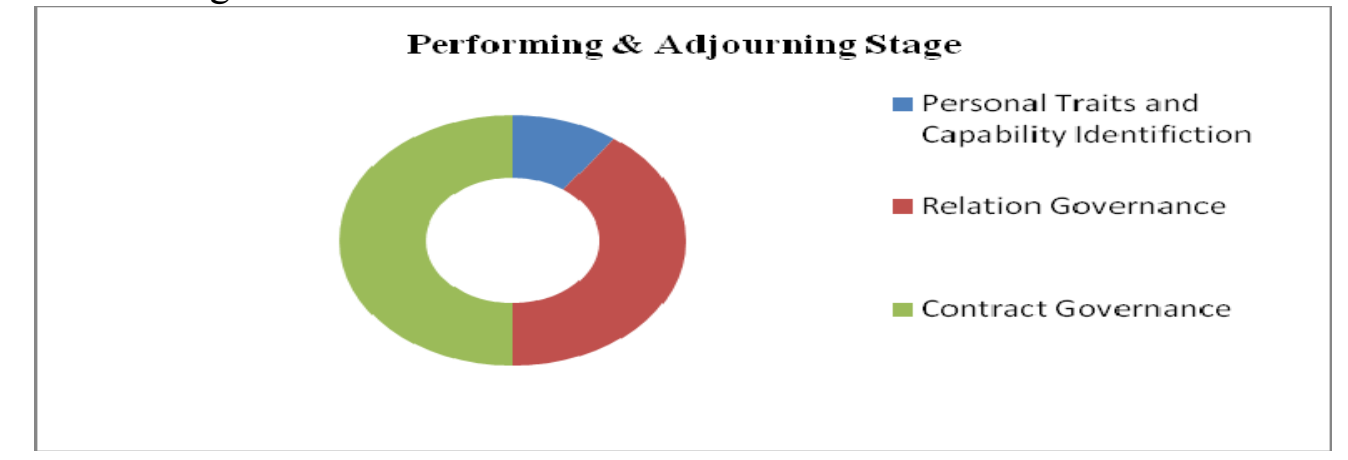

Figure 2 .Motivation Model for Performing \& Adjourning Stage 


\section{Integrated and Dynamic Motivation Model Construction}

By the above definition and related research, we know that the establishment and development of enterprises business is a dynamic and developing process, motivation methods include selection of team members, relation management and contract management. So the motivation focus is adjusted based on the changing process at each development stage of entrepreneurial team. According to each stage we attempt to establish an integrated motivation model in Figure 3 to capture the dynamic character of entrepreneurial team development.

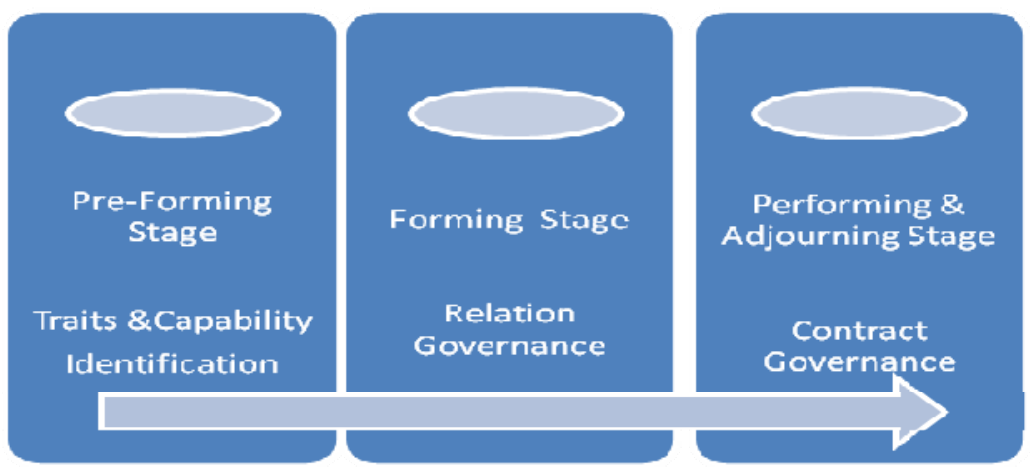

Figure 3. Integrated Motivation Model for Entrepreneurial Team

The three motivation methods are coexistent at each stage, but with different stages of team development, three kinds of incentives, are of different the importance and proportion which should be made adjustments accordingly. At pr-forming stage Forming stage, performing and adjourning stage of the development entrepreneurial team, traits identification, relation governance and contract governance are dominant motivation, respectively.

\section{Summary}

Building motivation model which targets at the different stages of an innovative business is extremely important and challenging because of complex and dynamic nature of entrepreneurial teams. Through personal traits identification relation governance and contract governance at different developing stages the integrated motivation model establishes a frame work to set incentive and control mechanism, we try to construct and coordinate interactive behavior among entrepreneurial team members all of which will lead to the good performance and target attainment at both personal and team level.

\section{References}

[1] Kamm, J. B., Shuman, J. C., Seeger J. A., Nurick A. J., “Entrepreneurial Teams in New Venture Creation: A Research Agenda” , Entrepreneurship: Theory \& Practice, (1990)vol.14. no.4, 1990, pp7-17

[2] Cooper, A. C., Dunkelberg, W. C., Entrepreneurship and Paths to Business Ownership , Strategic Management Journal, (1986) vol.7. no.1, pp.53-68

[3] Cooney, T. M., What is an Entrepreneurial Team?International Small Business Journal, （2005 ) vol.23. no. 3 , pp.226-235

[4] Zhu Renhong, Dai Jilin and Zeng Chuhong ,A Study on the Evolution and Governance of Entrepreneurial Team in a Human Capital Perspective, Academic Research ( 2013) .vol.10 pp $81-85$ 